\title{
Safety of Transseptal Puncture for Access to the Left Atrium in Infants and Children
}

\author{
Matthias J. Müller ${ }^{1}$ D $\cdot$ David Backhoff ${ }^{1} \cdot$ Heike E. Schneider $^{1}$. Jana K. Dieks ${ }^{1}$. Julia Rieger ${ }^{1}$. Ulrich Krause ${ }^{1}$. \\ Thomas Paul ${ }^{1}$
}

Received: 4 October 2020 / Accepted: 18 December 2020 / Published online: 16 January 2021

(c) The Author(s) 2021

\begin{abstract}
Transseptal puncture (TSP) is a standard procedure to obtain access to the left heart. However, data on TSP in infants and children particularly with congenital heart defects (CHD) is sparse. Safety and efficacy of TSP in infants and children $<18$ years with normal cardiac anatomy and with CHD were assessed. 327 TSP were performed in a total of 300 individuals $<18$ years from 10/2002 to 09/2018 in our tertiary pediatric referral center. Median age at TSP was 11.9 years (IQR 7.8-15; range: first day of life to 17.9 years). 13 subjects were < 1 year. Median body weight was $43.8 \mathrm{~kg}$ (IQR 26.9-60; range: $1.8-121 \mathrm{~kg}$ ). CHD was present in 28/327 (8.6\%) procedures. TSP could be successfully performed in 323/327 (98.8\%) procedures and was abandoned in 4 procedures due to imminent or incurred complications. Major complications occurred in 4 patients. 3 of these 4 subjects were $\leq 1$ year of age and required TSP for enlargement of a restrictive atrial septal defect in complex CHD. Two of these babies deceased within $48 \mathrm{~h}$ after TSP attempt. The third baby needed urgent surgery in the cath lab. Pericardial effusion requiring drainage was noted in the forth patient ( $>1$ year) who was discharged well later. Minor complications emerged in 5 patients. The youngest of these individuals ( 0.3 years, $5.8 \mathrm{~kg}$ ) developed small pericardial effusion after anterograde ballon valvuloplasty for critical aortic stenosis. The remaining $4 / 5$ patients developed small pericardial effusion after ablation of a left-sided accessory atrioventricular pathway (6.1-12.2 years, $15.6-34.0 \mathrm{~kg})$. TSP for access to the left heart was safe and effective in children and adolescents $>1$ year of age. However, TSP was a high-risk procedure in small infants with a restrictive interatrial septum with need for enlargement of interatrial communication.
\end{abstract}

Keywords Transseptal puncture $\cdot$ Infants $\cdot$ Children $\cdot$ Congenital heart defect

$\begin{array}{ll}\text { Abbreviations } \\ \text { AF } & \text { Atrial fibrillation } \\ \text { AP } & \text { Accessory pathway } \\ \text { CHD } & \text { Congenital heart defect } \\ \text { d-TGA } & \text { D-Transposition of the great arteries } \\ \text { F } & \text { French } \\ \text { HLHS } & \text { Hypoplastic left heart syndrome } \\ \text { IQR } & \text { Interquartile range } \\ \text { ICE } & \text { Intracardiac echocardiography } \\ \text { LA } & \text { Left atrium } \\ \text { PE } & \text { Pericardial effusion } \\ \text { RF } & \text { Radiofrequency } \\ \text { SVT } & \text { Supraventricular tachycardia }\end{array}$

Matthias J. Müller

matthias.mueller@med.uni-goettingen.de

1 Department of Pediatric Cardiology and Intensive Care Medicine, Georg August University Medical Center, Robert-Koch-Str. 40, 37075 Göttingen, Germany
TEE Transesophageal echocardiography

TTE Transthoracic echocardiography

TSP Transseptal puncture

VSD Ventricular septal defect

\section{Introduction}

Since introduction into clinical practice in 1959, transseptal puncture (TSP) under fluoroscopic guidance using the Brockenbrough approach is a common procedure to obtain access to the left heart during cardiac catheterization. TSP offers the opportunity to a wide spectrum of diagnostic and interventional left heart procedures like catheter ablation, percutaneous mitral valvuloplasty or clip repair and left atrial appendage occlusion $[1,2]$. The target for TSP is the fossa ovalis which is typically localized in the center of the interatrial septum. Due to anatomical variations of the fossa ovalis, TSP may sometimes be challenging. Care must be 
taken to avoid potentially life-threatening complications as pericardial effusion and tamponade [2]. It is of note, that elective TSP in infants and children with normal cardiac anatomy has been described as feasible and safe with a low complication rate $(0.3-2.3 \%)$ [3-5] comparable with the complication rate of TSP in adults [6]. It is not yet clear if these results can be adopted for children with urgent need of TSP especially in small infants with congenital heart defects. The purpose of the present study was to examine the risk of TSP in a remarkable number of infants and children $<18$ years with normal heart anatomy and congenital heart defects (CHD).

\section{Patients and Methods}

For the present study, data of all infants and children with transseptal access to the left atrium (LA) via transseptal puncture (TSP) during cardiac catheterization in our tertiary pediatric referral center between 10/2002 and 09/2018 were collected. Subjects with a patent formen ovale or an atrial septal defect allowing catheter access to the LA were not included into this study. Informed consent had been obtaiend from the legal guardians of all individuals. The study had been approved by the local scientific committee of the Childen's Hospital of Georg-August-University Medical Center, Göttingen, Germany.
A total of 327 TSP were performed in 300 subjects $<18$ years of age. Median age was 11.9 years (IQR 7.8-15 years; range: first day of life to 17.9 years). 12 subjects were $\leq 1$ year of age. Median body weight was $43.8 \mathrm{~kg}$ (IQR 26.9-60 kg; range: $1.8-121 \mathrm{~kg}$ ) and median height was $154 \mathrm{~cm}$ (IQR 129-168 cm; range: 40-190 cm). Congenital heart defects were present in $28 / 327$ (8.6\%) procedures (Table 1).

\section{Transseptal Access to the Left Atrium}

Transseptal access to the left atrium was obtained using a Brockenbrough transseptal needle (Brockenbrough BRK, $98 \mathrm{~cm}$, St. Jude Medical/Abbott; Brockenbrough BRK-1, $73 \mathrm{~cm}$ St. Jude Medical/Abbott and Brockenbrough BRK-2, $56 \mathrm{~cm}$, St. Jude Medical/Abbott, respectively). Length of the Brockenbrough transseptal needle was selected depending on patients height. For TSP the Brockenbrough transseptal needle was advanced to the tip of a long sheath placed in the superior caval vein (SR-0/SL-1, $63 \mathrm{~cm}, 8$ French (F), St Jude Medical/Abbott or Agilis NXT steerable introducer, Abbot $8.5 \mathrm{~F}$ in all subjects with body weight of $>30 \mathrm{~kg}$ or 'Mullins' Fast-Cath ${ }^{\mathrm{TM}}, 6$ to $8 \mathrm{~F}$, St. Jude Medical/Abbott in all subjects with body weight of $\leq 30 \mathrm{~kg}$ ). All TSP were performed under fluoroscopic guidance using biplane fluoroscopy in right anterior oblique (RAO) $30^{\circ}$ and left anterior oblique (LAO) $60^{\circ}$ orientation. The sheath-dilator-transseptal needle

Table 1 Baseline characteristic of patients $(n=327)$

\begin{tabular}{|c|c|c|c|c|c|}
\hline & & All $(n=327)$ & TSP for ablation $(n=305)$ & $\begin{array}{l}\text { TSP for hemodynamic } \\
\text { intervention }(n=8)\end{array}$ & $\begin{array}{l}\text { TSP for diag- } \\
\text { nostic purpose } \\
(n=14)\end{array}$ \\
\hline Median age & Years (IQR) & $11.9(7.8-15)$ & $12.1(8.5-15.1)$ & $0.3(0.1-0.7)$ & $5.8(3.2-14.7)$ \\
\hline Median body weight & kg (IQR) & $43.8(26.9-60.5)$ & $44.7(29.6-60.5)$ & $4.6(3.0-7.3)$ & $17.0(12.8-53.3)$ \\
\hline Median height & $\mathrm{cm}(\mathrm{IQR})$ & $154(129-168)$ & $155(129-168)$ & $58(51-69)$ & $114(94-166)$ \\
\hline \multicolumn{6}{|l|}{ Congenital heart defects } \\
\hline None & $N(\%)$ & $299(91.4 \%)$ & $298(98 \%)$ & $0(0 \%)$ & $1(7.1 \%)$ \\
\hline VSD & $N(\%)$ & $1(0.3 \%)$ & 0 & 0 & $1(7.1 \%)$ \\
\hline d-TGA & $N(\%)$ & $1(0.3 \%)$ & 0 & $1(12.5 \%)$ & 0 \\
\hline Valvular aortic stenosis & $N(\%)$ & $8(2.4 \%)$ & $2(0.7 \%)$ & $2(0.25 \%)$ & $4(28.6 \%)$ \\
\hline Coarctation/shone complex & $N(\%)$ & $4(1.2 \%)$ & 0 & $1(12.5 \%)$ & $3(21.4 \%)$ \\
\hline HLHS & $N(\%)$ & $2(0.6 \%)$ & 0 & $2(0.25 \%)$ & 0 \\
\hline Fontan & $N(\%)$ & $3(0,9 \%)$ & $3(1 \%)$ & 0 & 0 \\
\hline Tetralogy of Fallot & $N(\%)$ & $1(0.3 \%)$ & 0 & 0 & $1(7.1 \%)$ \\
\hline Ebstein’s anomaly & $N(\%)$ & $1(0.3 \%)$ & $1(0.3 \%)$ & 0 & 0 \\
\hline $\mathrm{s} / \mathrm{p}$ mitral valve replacement & $N(\%)$ & $1(0.3 \%)$ & $1(0.3 \%)$ & 0 & 0 \\
\hline Pulmonary vein stenosis & $N(\%)$ & $5(1.5 \%)$ & 0 & $2(0.25 \%)$ & $3(21.4 \%)$ \\
\hline Pulmonary atresia & $N(\%)$ & $1(0.3 \%)$ & 0 & 0 & $1(7.1 \%)$ \\
\hline Minor complications & $N(\%)$ & $5(1.5 \%)$ & $4(1.3 \%)$ & $1(12.5 \%)$ & $0(0 \%)$ \\
\hline Major complications & $N(\%)$ & $4(1.2 \%)$ & $1(0.3 \%)$ & $3(37.5 \%)$ & $0(0 \%)$ \\
\hline
\end{tabular}

$d$-TGA d-Transposition of the great arteries, HLHS hypoplastic left heart syndrome, TSP transseptal puncture, VSD ventricular septal defect 
ensemble ("transseptal system") was pulled back into the right atrium with the transseptal system tip being directed towards the interatrial septum interrogating the fossa ovalis. The tip was advanced with gentle pressure in a superiorposterior fashion with the tip of the needle being advanced to the tip of the dilator ("blunt" approach). If gentle pressure failed to penetrate the interatrial septum, the tip of the transspetal needle was moved slightly forward in order to penetrate the interatrial septum ("sharp" approach). After the transseptal needle and the tip of the dilator had entered the left atrium, the sheath was pushed over the dilator/needle into the left atrium. The transseptal needle and the dilator were removed subsequently and oxygenated blood was aspirated via the sheath in order to confirm correct position in the left atrium as verified by fluoroscopy. Heparin (100 IE/ $\mathrm{kg}$ ) was administered following TSP in subjects with CHD while it had already been given before TSP in children with normal cardiac anatomy.

Any events that required additional to diagnostic procedures or therapy except standard of care, were considered as major complications while events without need for further treatment were classified as minor complications.

\section{Statistics}

Statistical analysis was performed using SPSS® 26.0 software (IBM, New York, USA). Numerical data is presented as median, interquartile range (IQR) and range. Differences between variables were calculated by Kruskal-Wallis-Test as appropriate. A value of $p<0.05$ was defined as level of statistical significance.

\section{Results}

All TSP procedures had been guided exclusively by biplane fluoroscopy without additional imaging tools such as transthoracic echocardiography (TTE), transesophageal echocardiography (TEE) or intracardiac echocardiography (ICE). Furthermore, microcatheters and radiofrequency (RF) energy for perforating interatrial septum was not used. TSP could successfully be performed in 323/327 (98.8\%) procedures and was abandoned in 4 procedures due to imminent or incurred complications.

For TSP, a $71 \mathrm{~cm}$ 'Brockenbrough' transseptal needle (BRK-1, St. Jude Medical, St. Paul, MN) was used in 279/327 (85.3\%) of procedures while the $56 \mathrm{~cm}$ needle (BRK-2, St. Jude Medical, St. Paul, MN) was used in 40/327 (12.2\%) procedures and the $98 \mathrm{~cm}$ needle (BRK, St. Jude Medical, St. Paul, MN) was used in 8/327 (2.4\%) procedures, respectively. Access to the LA was achieved with help of a SR-0/ SL-1 sheath in 240/327 (73.4\%) procedures and with a Agilis NXT steerable introducer in $8 / 327(2.4 \%)$ procedures while a 'Mullins'-sheath was used in 79/327 (24.2\%) procedures, respectively.

Main indication for TSP and access to the left atrium was catheter ablation of left sided supraventricular tachycardia (SVT) substrates in 305/327 (93.3\%) procedures. In 14/327 (4.3\%) procedures with CHD, LA access was required for preoperative diagnostics. In a total of $8 / 327$ (2.4\%) procedures in 7 patients, LA access was needed for a catheter intervention except from ablation. All these 7 children were aged $<1$ year. Interventions included balloon atrioseptostomy $(n=4)$, antegrade aortic valvuloplasty $(n=2)$ and dilatation of pulmonary vein stenosis $(\mathrm{n}=2)$.

Major complications occurred in 4/327 (1.2\%) of TSP procedures and were substantially more frequent among children with TSP for a hemodynamic intervention $(3 / 8 ; 37.5 \%)$ when compared with TSP for catheter ablation $(1 / 305 ; 0.3 \%$; $p<0.001)$ or diagnostic procedures $(0 / 14 ; 0.0 \%$; Table 1$)$. It is of note, that $3 / 4$ major complications occurred in children $<1$ year of age (Table 2). Individuals with major complications were significantly younger $(p=0.007)$, smaller $(p=0.008)$ and had less body weight $(p=0.011)$ than patients without complications (Fig. 1). In one newborn with hypoplastic left heart syndrome (HLHS) the restrictive interatrial communication could not be enlarged and the baby developed profound lactate acidosis after TSP without presence of a PE. This baby deceased during the procedure. $\mathrm{PE}$ and pericardial tamponade were noted in 2 other babies in whom TSP was needed for ballon atrioseptostomy in d-transposition of the great arteries (d-TGA) and HLHS, respectively. Urgent insertion of an pericardial drainage was needed in both infants. The fourth major complication occurred in an 11-year-old boy with structurally normal heart and SVT due to a left-sided accessory pathway (AP). In this patient TSP failed as the needle crossed the atrial wall causing significant PE with need for pericardial drainage. This patient was discharged in well condition three days after TSP.

A total of 5/327 (1.5\%) minor complications were noted which were uniformly small PEs without need for intervention (Table 3). Patients with minor complications had significantly less body weight than patients without complications $(p=0.029$, Fig. 1). A total of $4 / 5$ minor PE were noted after ablation of left-sided AP and in one 4-month-old boy after TSP for ballon-valvuloplasy of critical aortic valve stenosis not amenable for retrograde approach. PE resolved spontaneously in all of these cases within 2 days after the procedure and no further action was needed.

\section{Discussion}

Transseptal access to the left atrium (LA) is a standard procedure and allows a variety of interventions including atrial fibrillation (AF) ablation and mitral valve repair [1]. The 
Table 2 Patients with major complications during TSP

\begin{tabular}{|c|c|c|c|c|c|c|c|}
\hline \# & $\begin{array}{l}\text { Age at } \\
\text { TSP } \\
\text { (years) }\end{array}$ & $\begin{array}{l}\text { Body } \\
\text { weight } \\
(\mathrm{kg})\end{array}$ & CHD & TSP indication & Complication & PE drainage & Outcome \\
\hline 1 & 0.0 & 1.8 & HLHS & $\begin{array}{l}\text { Creation/enlargement of an } \\
\text { interatrial communication }\end{array}$ & $\begin{array}{l}\text { Severe lactate acidosis, circu- } \\
\text { latory arrest, no PE }\end{array}$ & None & Deceased during procedure \\
\hline 2 & 0.0 & 2.8 & HLHS & $\begin{array}{l}\text { Creation/enlargement of an } \\
\text { interatrial communication }\end{array}$ & $\begin{array}{l}\text { PE after erroneous punction } \\
\text { in LA roof, insertion of a } \\
\text { drainage, urgent surgical } \\
\text { septostomy and bilateral PA- } \\
\text { banding same day }\end{array}$ & Yes & Deceased next day after surgery \\
\hline 3 & 0.3 & 4.2 & d-TGA & $\begin{array}{l}\text { Creation/enlargement of an } \\
\text { interatrial communication }\end{array}$ & $\begin{array}{l}\text { PE after erroneous puncture } \\
\text { of the pulmonary artery, } \\
\text { pericardial tamponade, } \\
\text { urgent surgery in the cath } \\
\text { lab }\end{array}$ & Yes & $\begin{array}{l}\text { Arterial switch OP two months } \\
\text { later }\end{array}$ \\
\hline 4 & 11.5 & 45 & None & $\begin{array}{l}\text { Ablation of left sided acces- } \\
\text { sory pathway }\end{array}$ & $\begin{array}{l}\text { PE after erroneous puncture } \\
\text { of the pulmonary artery, } \\
\text { insertion of a drainage }\end{array}$ & Yes & $\begin{array}{l}\text { Discharged well three days after } \\
\text { TSP }\end{array}$ \\
\hline
\end{tabular}

$C H D$ congenital heart defect, $d$-TGA d-transposition of the great arteries, $H L H S$ hypoplastic left heart syndrome, $P E$ pericardial effusion, TSP transseptal puncture

Brockenbrough technique under fluoroscopic guidance and pressure monitoring is safe and effective in adult patients [6]. In infants and children atraumatic passage of the interatrial septum to the LA is often possible via a patent foramen ovale $[4,5,7]$. Safety of fluoroscopic guided TSP in children including those with CHD, however, is yet not well described. Complications were reported to occur in $0.72 \%$ procedures in adult patients [7] and in 2.3\% in children for RF catheter ablation $<30 \mathrm{~kg}$ and normal cardiac anatomy [3]. In contrast to these studies we included subjects with CHD in our analysis. The present study covers results of standardized TSP with use of dual plane fluoroscopy in infants with urgent TSP due to hemodynamic reasons in CHD, TSP for diagnostic procedures in patients with CHD and TSP for ablation of left sided targets. In our patient population including infants and small children, overall, TSP under fluoroscopic guidance was safe and effective with a total of $1.2 \%$ major and $1.5 \%$ minor complications. There was, however, a significant number of complications (minor complications $12.5 \%$, major complications $37.5 \%$ ) in babies $<1$ year of age and a body weight $<5 \mathrm{~kg}$ with urgent TSP due to severe congenital heart defects needing access to the left heart for hemodynamical reasons as well as ballon atrioseptosomy of a restrictive interatrial septum or antegrade valvuloplasty of the aortic valve.

Additional imaging tools were not used in our series. In general, structural abnormities like a thick-/fibrotic or aneurysmatic interatrial septum in patients with CHD may present a challenge for TSP [8]. For these procedures, safety and efficacy of TSP may be improved by additional imaging tools like TTE [8], TEE [9] or ICE [10]. TEE and ICE reflect intracardial anatomy in more detail than TTE or fluoroscopy alone [9, 10]. Both, TEE and ICE, however, are not free from complications and may not be feasible at all due to hemodynamic compromise in critically ill babies needing urgent TSP. In addition, another experienced operator is necessary for TTE or TEE in these situations which may not be available in urgent interventions [11]. TEE associated complications have been reported in approximately $1 \%$ of pediatric patients and include transient difficulty in swallowing, shifting the endotracheal tube, transient airway obstruction, transient hoarseness and ventilation problems [12]. ICE is free from risk of esophageal injury and can be performed by the same operator [10]. Yet, ICE needs an additional venous sheath to accommodate a 6-10 F catheter [10] which may increase the risk of vascular complications. Despite these potential complications, TEE and ICE may be helpful additional tools for transseptal puncture in difficult anatomical conditions $[10,12]$ and maybe an option for successful TSP in small, critically ill babies.

In particular situations the use of a RF guidewire and microcatheter may help in performing a successful TSP. The RF technique utilizes high-frequency electrical current in contrast to mechanical energy using the traditional Brockenbrough approach. RF may be delivered directly via the tip of the transseptal needle for TSP in small CHD patients [8]. In a series of 7 patients with CHD $<1$ year of age the procedure was successful in 6/7 infants. Heating the transseptal needle may cause in coring the cardiac tissue into the tip of the open-ended needle with the risk of systemic embolization [13]. Furthermore, size of the hole created by RF was larger than after conventional puncture [14]. Finally, RF puncture inherits a higher risk of bleeding complications by perforating other structures than the interatrial septum e.g. the free 
Fig. 1 Age, height and body weight at the time of TSP for patients without complications (green box diagram), with minor complications (blue box diagram) and with major complications (red box diagram). Individuals with major complications were significantly younger $(p=0.007)$, smaller $(p=0.008)$ and lighter $(p=0.011)$ than patients without complications at time of TSP. In addition, patients with minor complications had less body weight than patients free from complications $(p=0.029)$
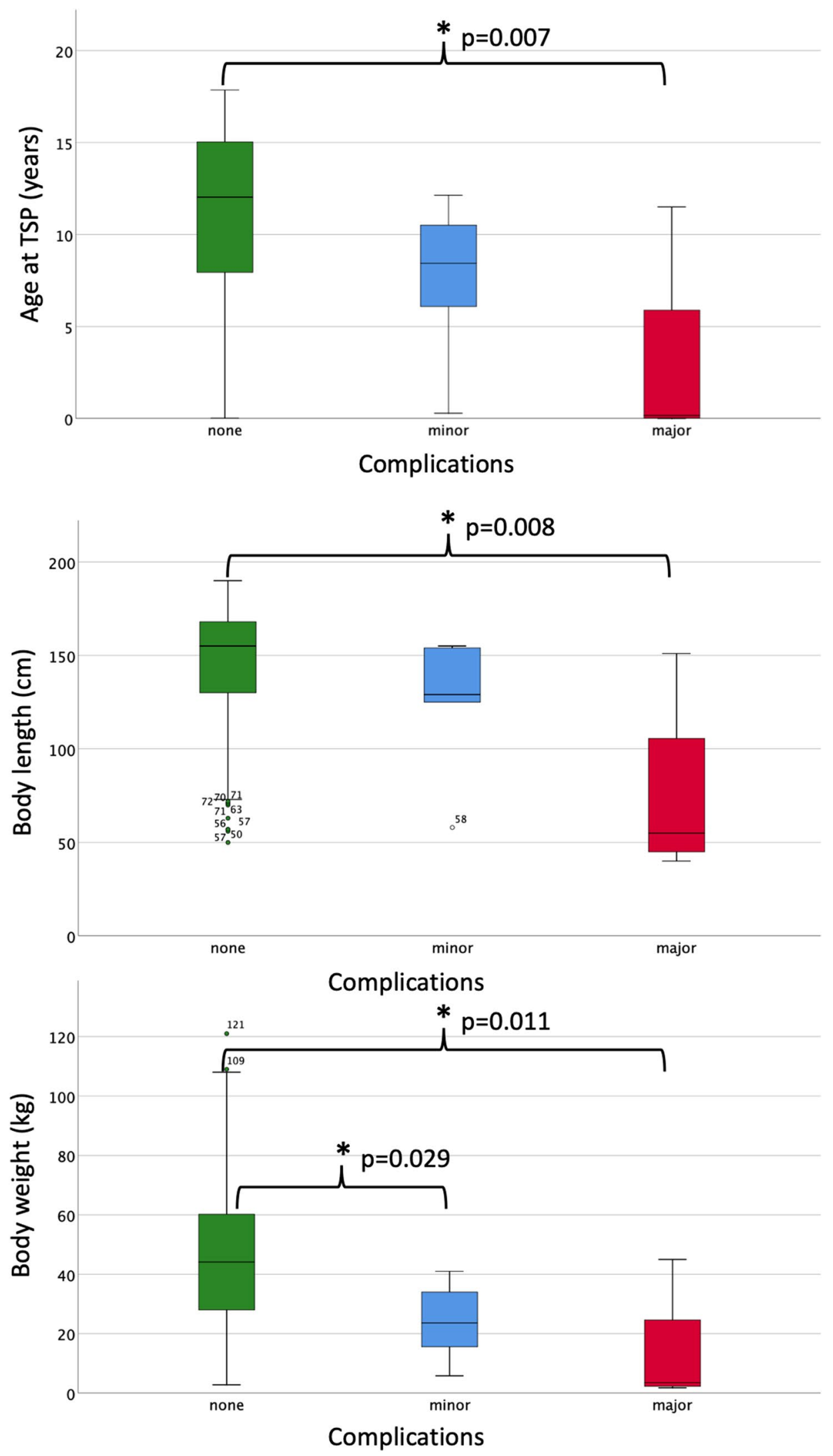
Table 3 Patients with minor complications during TSP

\begin{tabular}{|c|c|c|c|c|c|c|c|}
\hline$\#$ & $\begin{array}{l}\text { Age at } \\
\text { TSP } \\
\text { (years) }\end{array}$ & $\begin{array}{l}\text { Body } \\
\text { weight } \\
(\mathrm{kg})\end{array}$ & CHD & TSP indication & Complication & PE drainge & Outcome \\
\hline 5 & 0.3 & 5.8 & Aortic stenosis & $\begin{array}{l}\text { Balloon valvuloplasty of } \\
\text { a critical valvular aortic } \\
\text { stenosis not amenable } \\
\text { for retrograde transaortic } \\
\text { approach }\end{array}$ & $\begin{array}{l}\text { Small PE }(3-4 \mathrm{~mm}) \text { after } \\
\text { erroneous puncture, no } \\
\text { increase of PE, successful } \\
\text { second TSP }\end{array}$ & None & $\begin{array}{l}\text { Ross-Konno operation } \\
3 \text { years later }\end{array}$ \\
\hline 6 & 6.1 & 34 & None & $\begin{array}{l}\text { Ablation of left sided acces- } \\
\text { sory pathway }\end{array}$ & $\begin{array}{l}\text { Small PE }(3 \mathrm{~mm}) \text { after } \\
\text { erroneous puncture in } \\
\text { pericardial space, no } \\
\text { enlargement of the PE and } \\
\text { successful second TSP }\end{array}$ & None & Discharged 3 days later \\
\hline 7 & 8.4 & 23.6 & None & $\begin{array}{l}\text { Ablation of left sided acces- } \\
\text { sory pathway }\end{array}$ & $\begin{array}{l}\text { Erroneous puncture in } \\
\text { pericardial space, no PE } \\
\text { detectable, no second } \\
\text { TSP due to low conduc- } \\
\text { tion properties of the left } \\
\text { sided AP }\end{array}$ & None & Discharged 2 days later \\
\hline 8 & 10.4 & 15.6 & None & $\begin{array}{l}\text { Ablation of left sided acces- } \\
\text { sory pathway }\end{array}$ & $\begin{array}{l}\text { Recurrent SVT } 4 \mathrm{~h} \text { after } \\
\text { ablation; on Echocardiog- } \\
\text { raphy small PE (3-4 mm) }\end{array}$ & None & Redo ablation after 5 months \\
\hline 9 & 12.1 & 41 & None & $\begin{array}{l}\text { Ablation of left sided acces- } \\
\text { sory pathway }\end{array}$ & $\begin{array}{l}\text { Small circular PE }(4 \mathrm{~mm}) \\
\text { after erroneous puncture } \\
\text { in pericardial space }\end{array}$ & None & Discharged 4 days later \\
\hline
\end{tabular}

$C H D$ congenital heart defect, $P E$ pericardial effusion, $T S P$ transseptal puncture

atrial wall. Nevertheless, perforating the interatrial septum with a microcatheter, is less invasive than perforating with needle-sheath-system [14].

Microcatheter assisted perforation of the interatrial septum has been shown to be an effective alternative to conventional Brockenbrough approach and feasible with and without RF [14-16]. It is an attractive alternative for perforating the interatrial septum in high risk patients $[15,16]$.

In contrast to the TSP complications in small babies with $\mathrm{CHD}$, only one severe complication (PE requiring drainage; $0.3 \%$ ) occurred among the patients receiving TSP for elective ablation of left-sided SVT substrates. This low complication rate of elective TSP is comparable to a previous report with a comparable number of TSP in pediatric electrophysiology procedures [4] and underlines the safety of TSP during elective procedures in children.

In conclusion, access to the left heart was safe and effective in subjects $>1$ year of age requiring access to the left heart for elective catheter ablation of left-sided tachycardia substrates or diagnostic procedures in patients with CHD. In contrast to this, TSP was a high-risk procedure in critically ill infants with a restrictive intraatrial septum and need for enlargement of the intraatrial communication. TSP under echocardiographic guidance additional to fluoroscopy as well as perforating the interatrial septum using microcatheter with or without RF may help in performing a successful procedure in individuals with complex interatrial anatomy and thick or tenting interatrial septum. A surgical back-up should be present, whenever an urgent TSP is performed in a small infant with CHD.

\section{Limitations}

This study is limited by its retrospective single center design such as its small number of subjects with CHD and TSP for hemodynamic intervention and TSP for diagnostic purpose. Furthermore, the complication rate of TSP is highly dependent on the operators experience. In our setting emergency TSP in small patients $<1$ year of age was exclusively performed by well experienced interventional pediatric cardiologists. Findings may therefore underestimate the real complication rate of TSP in critically ill children with CHD $<1$ year of age.

Funding Open Access funding enabled and organized by Projekt DEAL. No external funding was secured for this study.

\section{Compliance with Ethical Standards}

Conflict of interest The authors declare that they have no conflict of interest. 
Open Access This article is licensed under a Creative Commons Attribution 4.0 International License, which permits use, sharing, adaptation, distribution and reproduction in any medium or format, as long as you give appropriate credit to the original author(s) and the source, provide a link to the Creative Commons licence, and indicate if changes were made. The images or other third party material in this article are included in the article's Creative Commons licence, unless indicated otherwise in a credit line to the material. If material is not included in the article's Creative Commons licence and your intended use is not permitted by statutory regulation or exceeds the permitted use, you will need to obtain permission directly from the copyright holder. To view a copy of this licence, visit http://creativecommons.org/licenses/by/4.0/.

\section{References}

1. Ross J Jr (2008) Transseptal left heart catheterization a 50-year odyssey. J Am Coll Cardiol 51(22):2107-2115

2. Tzeis S, Andrikopoulos G, Deisenhofer I, Ho SY, Theodorakis G (2010) Transseptal catheterization: considerations and caveats. Pacing Clin Electrophysiol 33(2):231-242

3. Yoshida S, Suzuki T, Yoshida Y, Watanabe S, Nakamura K, Sasaki T et al (2016) Feasibility and safety of transseptal puncture procedures for radiofrequency catheter ablation in small children weighing below $30 \mathrm{~kg}$ : single-centre experience. Europace 18(10):1581-1586

4. von Alvensleben JC, Dick M 2nd, Bradley DJ, LaPage MJ (2014) Transseptal access in pediatric and congenital electrophysiology procedures: defining risk. J Interv Card Electrophysiol 41(3):273-277

5. Ehrlinspiel DM, Gass M, Balmer C (2017) Transseptal puncture for radiofrequency catheter ablations of left-sided arrhythmias in a paediatric population. Cardiol Young 27(2):267-272

6. Matoshvili Z, Bastani H, Bourke T, Braunschweig F, Drca N, Gudmundsson K et al (2017) Safety of fluoroscopy-guided transseptal approach for ablation of left-sided arrhythmias. Europace 19(12):2023-2026

7. Koca S, Akdeniz C, Tuzcu V (2019) Transseptal Puncture for Catheter Ablation in Children. Pediatr Cardiol 40(4):799-804
8. Gowda ST, Qureshi AM, Turner D, Madan N, Weigand J, Lorber $R$ et al (2017) Transseptal puncture using surgical electrocautery in children and adults with and without complex congenital heart disease. Catheter Cardiovasc Interv 90(3):E46-E54

9. Cheung YF, Leung MP, Lee J, Yung TC (1999) An evolving role of transesophageal echocardiography for the monitoring of interventional catheterization in children. Clin Cardiol 22(12):804-810

10. Enriquez A, Saenz LC, Rosso R, Silvestry FE, Callans D, Marchlinski FE et al (2018) Use of intracardiac echocardiography in interventional cardiology: working with the anatomy rather than fighting it. Circulation 137(21):2278-2294

11. Manolis AS (2017) Transseptal access to the left atrium: tips and tricks to keep it safe derived from single operator experience and review of the literature. Curr Cardiol Rev 13(4):305-318

12. Ayyildiz P, Guzeltas A, Tanidir IC, Kasar T, Ozturk E, Ergul Y (2016) Transesophageal echocardiography experience in thepediatric age group in a tertiary cardiac center. Turk J Med Sci 46(4):1155-1161

13. Greenstein E, Passman R, Lin AC, Knight BP (2012) Incidence of tissue coring during transseptal catheterization when using electrocautery and a standard transseptal needle. Circ Arrhythm Electrophysiol 5(2):341-344

14. Khan JM, Rogers T, Eng MH, Lederman RJ, Greenbaum AB (2018) Guidewire electrosurgery-assisted trans-septal puncture. Catheter Cardiovasc Interv 91(6):1164-1170

15. de Asmundis C, Chierchia GB, Sarkozy A, Paparella G, Roos M, Capulzini L et al (2009) Novel trans-septal approach using a Safe Sept J-shaped guidewire in difficult left atrial access during atrial fibrillation ablation. Europace 11(5):657-659

16. Wadehra V, Buxton AE, Antoniadis AP, McCready JW, Redpath CJ, Segal OR et al (2011) The use of a novel nitinol guidewire to facilitate transseptal puncture and left atrial catheterization for catheter ablation procedures. Europace 13(10):1401-1405

Publisher's Note Springer Nature remains neutral with regard to jurisdictional claims in published maps and institutional affiliations. 